\title{
$\widehat{A}$ Madridge \\ madridge Journal of Diabetes
}

Research Article

Open Access

\section{Substantial and Sustained HbA1c reductions in Australian Insulin Pump Services for Adults with Type 1 Diabetes. Benefit also evident for Older and High HbAlc Subjects}

Daniel A Calandro ${ }^{1,2 \star}$, Andrzej S Januszewski ${ }^{1,2 *}$, Kaya K Cuper²,3, Marilyn Burgess ${ }^{2}$, Jodie Horsburgh ${ }^{2}$, Margaret Loh $^{4}$, Kathleen Steele ${ }^{4}$, Elizabeth Mulrooney ${ }^{4}$, Fiona Weedon ${ }^{5}$, Brenda Cayzer ${ }^{5}$, Balasubramanian Krishnamurthy ${ }^{4}$, Richard J MacIsaac ${ }^{2,4}$, Glenn M Ward ${ }^{2,4}$, David N O'Neal ${ }^{2,4,5}$ and Alicia J Jenkins ${ }^{1,2,4}$

${ }^{1}$ NHMRC Clinical Trials Centre, University of Sydney, Camperdown, NSW, Australia

${ }^{2}$ Department of Medicine, University of Melbourne, Fitzroy, VIC, Australia

${ }^{3}$ Lake Forest College, Lake Forest, IL, USA

${ }^{4}$ Department of Endocrinology and Diabetes, St Vincent's Hospital, Melbourne, VIC, Australia

${ }^{5}$ Mercy Hospital, Werribee, VIC, Australia

\section{Article Info}

\section{*Corresponding authors: \\ Daniel A Calandro \\ NHMRC Clinical Trials Centre \\ University of Sydney, Camperdown, NSW \\ Australia}

\section{Andrzej S Januszewski \\ Department of Medicine \\ University of Melbourne, Fitzroy, VIC \\ Australia \\ E-mail: andrzej.januszewski@ctc.usyd.edu.au}

Received: August 28, 2016

Accepted: October 17, 2016

Published: October 21, 2016

Citation: Calandro DA, Januszewski AS, Cuper KK, et al. Substantial and Sustained $\mathrm{HbA} 1 \mathrm{c}$ reductions in Australian Insulin Pump Services for Adults with Type 1 Diabetes. Benefit also evident for Older and High HbA1c Subjects. Madridge J Diabetes. 2016; 1(1): 23-28.

doi: $10.18689 / \mathrm{mjd}-1000104$

Copyright: $\odot 2016$ The Author(s). This work is licensed under a Creative Commons Attribution 4.0 International License, which permits unrestricted use, distribution, and reproduction in any medium, provided the original work is properly cited.

Published by Madridge Publishers
Keywords: HBA1c; Type 1 Diabetes; Insulin Pump; Exogenous Insulin.

\section{Introduction}

People with Type 1 diabetes (T1D) can choose to deliver their essential exogenous insulin by multiple daily insulin injections (MDI) or by continuous subcutaneous insulin infusion (CSII) / pump therapy. Unfortunately, cost and logistic considerations of CSII therapy still remain as barriers to many patients [1,2], with approximately $10 \%$ of Australia's $\approx 122,000$ people with T1D using insulin pumps. Whilst flexibility and quality of life for people with T1D are extremely important, many healthcare and funding agencies regard glycaemic control as the outcome of primary importance.

A meta-analysis of randomised controlled trials, not clinical practice audits, of CSII vs. MDI reported that relative to $\mathrm{MDI}$ use, $\mathrm{CSII}$ therapy lowers $\mathrm{HbA} 1 \mathrm{c}$ levels by a mean of $0.25 \%$ $(2.7 \mathrm{mmol} / \mathrm{mol})$ in adults with T1D [3]. Published CSII outcomes in Australia include: results of a user survey by the Australian Institute of Health and Welfare (AIHW) [1], a small followup study of CSII use in a rural setting in Infu Systems Asia [4], an audit of one tertiary referral clinic [5], and national diabetes conference abstracts re early pump experiences [6,7]. We now report results of a quality assurance (QA) audit of CSII clinical outcomes from three linked Victorian (Australia) services with some endocrinologists, diabetes educators and dietician staff in common. These clinics are all bulk-billing (i.e. covered by the national health scheme and at no out-of-pocket cost to patients). The time-frame relates to when CSII use was not associated with real-time continuous glucose monitoring (CGM) use, which may further improve glycaemic control beyond insulin pump alone, but are self-funded.

\section{Methods}

\section{Subjects and CSII Services}

Adults with T1D who commenced CSII therapy during or after 2003 at one of three collaborating services (in an Insulin Pump Clinic in the University of Melbourne, Department of Medicine St. Vincent's Hospital; a clinic run by St. Vincent's (Public) Hospital Department of Endocrinology and Diabetes, Melbourne; and a clinic at the Werribee Mercy Hospital Diabetes Service). Follow-up was up until mid-2011. The University of Melbourne based 
pump clinic provides a service to other endocrinologists to initiate and stabilise adults on CSII therapy using a shared care model, in which once stabilised the patients return to the sole care of their referring endocrinologist or have an annual followup visit only. This service provides pre- and post-pump start support. Pump initiations as a day or overnight patient are usually performed by the St Vincent's or Werribee public hospital teams or by admission to a nearby private hospital. The two public hospital clinics provide full CSII pre-education, CSII initiation and follow-up for their own patients, who are usually seen in outpatients about every three months, and more often during the pump stabilisation phase. Consultations are an admixture of small group and individual education, with carbohydrate counting being assessed, and if necessary taught, pre-CSII initiation. For inclusion in this audit subjects had to have been on CSII therapy for at least three months.

Of the 103 T1D adults commencing CSII use adequate data for inclusion were available for 77 subjects. Twenty-six subjects could not be included due to either uncertainty about their insulin pump start date $(n=6)$, and/or a missing age of T1D diagnosis $(n=17)$, and/or inability to obtain both baseline and follow-up biochemical measures $(n=19)$.

\section{Data collected}

Age, diabetes duration, weight and height and blood pressure were recorded from medical records. Laboratory tests were performed by NATA accredited public hospital or private pathology laboratories and results obtained by review of (paper or electronic) medical records, or via contact with the pathology laboratories or treating physician. Data related to hypoglycaemia and hospital admissions were not collected.

\section{Statistics}

Data were recorded in MS Excel (2007) and de-identified data analysed to provide descriptive statistics. Statistical significance was taken at $p<0.05$. The nadir (lowest HbA1c since CSII commencement), time taken to achieve it and first time at or since CSII commencement that a patient achieved a HbA1c level below $7 \%$ were identified for each patient. The mean annual $\mathrm{HbA} 1 \mathrm{c}$ for each patient was calculated from his or her $\mathrm{HbA} 1 \mathrm{c}$ values measured each year post-CSII initiation. The mean value for the entire group or subgroup for each year was then calculated as the mean of the individual means. Using the same (annual mean of available measures) method we calculated the annual means for blood lipids, urinary albumin/creatinine ratio (ACR). As they were measured more frequently we calculated blood pressure and weight (measured at the clinics) at 4-monthly intervals for up to two years (as data were sparse thereafter). For comparisons of continuous variables between two groups unpaired t-tests were utilized, and ANOVA with Tukey post-hoc tests.

\section{Results}

\section{Subjects}

Clinical and biochemical characteristics are shown in Table 1. Baseline characteristics of the 26 subjects for whom insufficient data were available to enable inclusion in the audit did not differ significantly from the 77 subjects described in Table 1. There was a wide range of age and T1D duration at the time of CSII commencement (Table 1 and Figure 1), and there were more female than male subjects commencing CSII. The group was relatively free of vascular complications, with only two patients having increased albuminuria, and four subjects having proliferative diabetic retinopathy. No subjects had known cardiovascular disease.

Table 1. Clinical demographics of adults with T1D (on MDI therapy) at CSII commencement.

\begin{tabular}{|c|c|}
\hline Parameter & \\
\hline $\mathrm{n}$ & 77 \\
\hline$\%$ Female & 75 \\
\hline Age (yrs) & $38 \pm 12$ \\
\hline T1DM duration (yrs) & $17 \pm 9$ \\
\hline HbA1c (\%) & $7.8 \pm 1.2$ \\
\hline $\mathrm{HbA1c}(\mathrm{mmol} / \mathrm{mol})$ & $61.9 \pm 12.6$ \\
\hline $\mathrm{HbA1c}<7 \%(n / \%)$ & $15 / 19$ \\
\hline $\operatorname{BMI}\left(\mathrm{kg} / \mathrm{m}^{2}\right)$ & $28.2 \pm 4.7$ \\
\hline \multicolumn{2}{|l|}{ BMI categories } \\
\hline $21-25 \mathrm{~kg} / \mathrm{m}^{2}(\%)$ & 26 \\
\hline $25-30 \mathrm{~kg} / \mathrm{m}^{2}(\%)$ & 41 \\
\hline$>30 \mathrm{~kg} / \mathrm{m}^{2}(\%)$ & 33 \\
\hline \multicolumn{2}{|l|}{ Lipids } \\
\hline Total Cholesterol (mmol/L) & $4.7 \pm 0.9$ \\
\hline TG (mmol/L) & $0.9(0.6,1.4)$ \\
\hline $\mathrm{LDL}-\mathrm{C}(\mathrm{mmol} / \mathrm{L})$ & $2.6 \pm 0.9$ \\
\hline $\mathrm{HDL}-\mathrm{C}(\mathrm{mmol} / \mathrm{L})$ & $1.6 \pm 0.4$ \\
\hline Urinary ACR (mg/mmol) & $0.12(0.07,0.40)$ \\
\hline
\end{tabular}

Data are mean \pm SD or median $(L Q, U Q)$.

Figure 1. Panel A: Distribution (\%) of the age (years) of adults with Type 1 diabetes at time of CSII commencement. Panel B: Distribution (\%) of the Type 1 diabetes duration (years) at time of CSII commencement
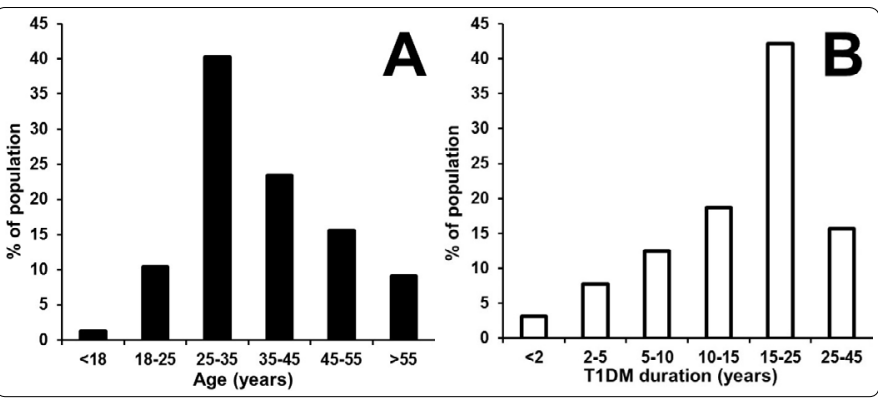

All but three subjects (who used a twice daily insulin injection regimen) were using a basal bolus $\mathrm{MDI}$ regimen preCSII therapy, usually basal flat profile insulins of Lantus or Levemir and a rapid acting insulin such as Novorapid or Humalog or Apidra. Whilst not recorded for each subject, in our clinic the average daily insulin dose reduction for CSII therapy is approximately $20-25 \%$ from that used when on MDI. All insulin pumps were acquired via private health insurance. Common indications for CSIl therapy were to improve glycaemia, including reducing risk of severe hypoglycaemia, for some women to improve glycaemia prepregnancy, and to improve lifestyle flexibility. All subjects obtained their pump consumables via the Australian National Diabetes Services Scheme (NDSS). No subject was regularly using continuous glucose monitoring. 


\section{HbA1c}

There were no statistically significant differences in CSII benefit based on $\mathrm{HbA} 1 \mathrm{c}$ levels by gender.

\section{Greater $\mathrm{HbA1c}$ reductions in CSII subjects starting with higher $\mathrm{HbA1c}$ levels}

The mean $\pm S D H b A 1 \mathrm{c}$ for the entire group fell from $7.8 \pm 1.2 \%(62 \pm 13 \mathrm{mmol} / \mathrm{mol})$ to a nadir of $6.7 \pm 0.8 \%$ $(50 \pm 9 \mathrm{mmol} / \mathrm{mol}), p<0.001$, over a mean $\pm S D$ of $17 \pm 20$ months. In contrast, in a reference group of $49 \mathrm{MDI}$ users (from the same clinical services) of similar age, sex, BMI and diabetes duration, mean \pm SD HbA1c over $39.7 \pm 31.7$ months did not change significantly from $8.0 \pm 1.4 \%(64 \pm 15 \mathrm{mmol} /$ $\mathrm{mol})$ to $7.8 \pm 1.2 \%(62 \pm 13 \mathrm{mmol} / \mathrm{mol}), \mathrm{p}=0.20)$.

The subjects $\mathrm{HbA} 1 \mathrm{c}$ response with CSII therapy was evaluated based on their starting $\mathrm{HbA} 1 \mathrm{c}$ level. There was a negative univariate correlation between pre-CSII $\mathrm{HbA} 1 \mathrm{c}$ level and the HbA1c drop at the HbA1c nadir ( $r=-0.76 ; p<0.0001)$. There was also a positive univariate correlation between pre$\mathrm{CSII} \mathrm{HbA1c}$ level and the value of the HbA1c nadir ( $r=0.42$, $p<0.0001$ ), both regardless of the time the nadir was reached. As shown in Figure 2, there were significant relationships between the tertile of $\mathrm{HbA} 1 \mathrm{c}$ at CSII commencement and the size of $\mathrm{HbA} 1 \mathrm{c}$ levels reduction.

Figure 2. Subjects divided by tertiles of $\mathrm{HbA} 1 \mathrm{c}$ at CSII start, stating the average $\mathrm{HbA} 1 \mathrm{c}$ at CSII commencement, and showing the drop

in $\mathrm{HbA} 1 \mathrm{c}$ from pre-pump to nadir (lowest $\mathrm{HbA1c}$ ) and time to achieve it. The numbers of subjects in each tertile from lowest to highest $\mathrm{HbA} 1 \mathrm{c}$ level were 27, 25 and 25 . Significance $\mathrm{p}$ shown vs. baseline and ANOVA for trend.

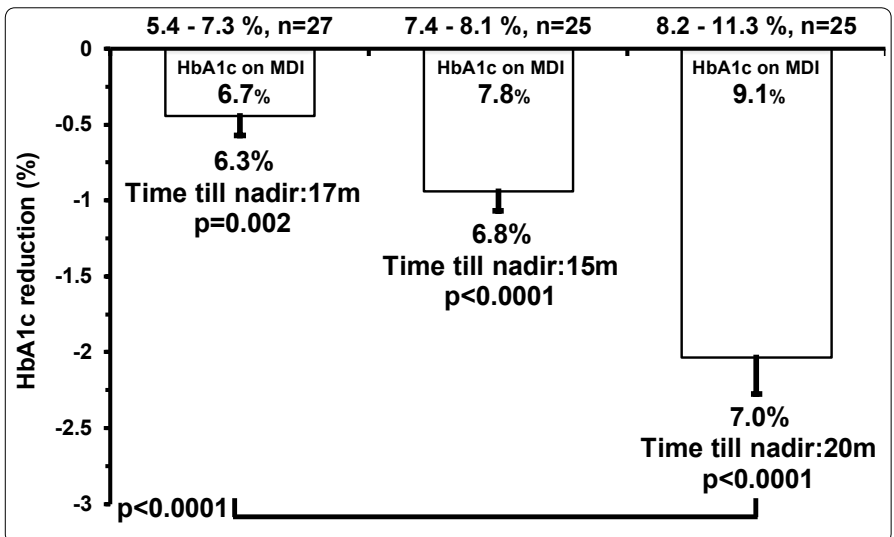

As shown in Figure 2, the higher the mean $\mathrm{HbA} 1 \mathrm{c}$ at CSII commencement, the larger the drop in $\operatorname{HbA} 1 c(p<0.0001)$, with all groups reaching similar $\mathrm{HbA} 1 \mathrm{c}$ nadirs, ranging between a mean of $6.3 \%(45 \mathrm{mmol} / \mathrm{mol})$ and $7.0 \%(53 \mathrm{mmol} /$ mol).The highest $\mathrm{HbA} 1 \mathrm{c}$ group tended to take longer to reach their HbA1c nadir, but the time differences were not statistically significant.

\section{Similar HbA1c reductions on CSII across age groups}

As shown in Figure 3, all tertiles based on patient age at CSII initiation dropped their $\mathrm{HbA} 1 \mathrm{c}$ levels significantly from baseline.

There were no statistically significant differences in age related starting $\mathrm{HbA} 1 \mathrm{c}$ level, $\mathrm{HbA} 1 \mathrm{c}$ reduction, nadir $\mathrm{HbA} 1 \mathrm{c}$ or time taken to achieve $\mathrm{HbA} 1 \mathrm{c}$ nadir, though the oldest group tended to take longer to reach their $\mathrm{HbA1c}$ nadir.

Figure 3. Subjects divided by tertiles of age at CSII commencement, stating the age range at CSII commencement (and the number per tertile), and showing the drop in $\mathrm{HbA} 1 \mathrm{c}$ from pre to nadir, and time to achieve it. Significance $p$ showed vs. baseline and ANOVA for trend.

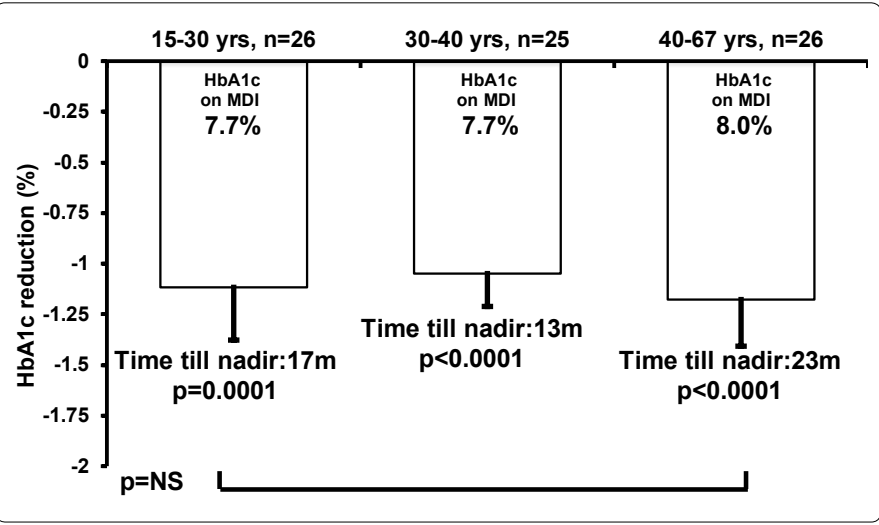

\section{Inverse relationship between diabetes duration and $\mathrm{HbA1c}$ reduction with CSII}

Whilst there was not major difference in $\mathrm{HbA} 1$ c improvement related to gender and age at CSII commencement T1D duration was related to $\mathrm{HbA} 1 \mathrm{c}$ benefit. Participants with shorter T1D duration ( $\leq 12$ years at CSII commencement) achieved a larger drop in $\mathrm{HbA} 1 \mathrm{C}(1.8 \pm 1.4 \%)$ vs. those with intermediate T1D duration $(12-20$ years $)(0.9 \pm 0.8 \%, p=0.007)$ vs. those with longer ( $>20$ years)T1D duration $(1.0 \pm 1.0 \%, p=0.02)$.

\section{Achievement of $\mathrm{HbA1c}<7 \%(53 \mathrm{mmol} / \mathrm{mol})$}

Pre-CSII use, only $19 \%$ of subjects had a $\mathrm{HbA} 1 \mathrm{c}<7 \%$ $(53 \mathrm{mmol} / \mathrm{mol})$, whereas $69 \%$ achieved an $\mathrm{HbA} 1 \mathrm{c}<7 \%$ $(53 \mathrm{mmol} / \mathrm{mol})$ on CSII at least once during follow-up. The percent with $\mathrm{HbA} 1 \mathrm{c}<7 \%(53 \mathrm{mmol} / \mathrm{mol})$ at years one through four on CSII therapy were $40 \%, 44 \%, 40 \%, 46 \%$ (in 73, 57, 48 and 39 subjects) respectively, which was significantly greater than that at baseline. At baseline 16 subjects had $\mathrm{HbA} 1 \mathrm{c}<7 \%$. The number reaching this $\mathrm{HbA} 1 \mathrm{c}$ target for the first time at year 1 and year 2 were 21 and 3 respectively. The number achieving $\mathrm{HbA} 1 \mathrm{c}<7 \%$ for the first time in years 3 and 4 were only one each year. Only two new subjects reached this target in year 5 , only one in year 6 and none reached this target for the first time in years 7 and 8.

\section{HbA1c levels over time on CSII}

Mean $\mathrm{HbA} 1 \mathrm{c}$ of the group pre-CSII commencement and for the first two years after CSII initiation and for up to eight years, are shown in Figure 4.

Panel A shows the mean group $\mathrm{HbA} 1 \mathrm{c}$ data for the first two years at $\approx 4$-month intervals post-CSII commencement, with the lowest $\mathrm{HbA} 1 \mathrm{c}$ being at 8-12 months. Panel B shows the data at annual intervals for up to eight years post-CSII commencement. The lowest annual HbA1c (relative to MDI therapy) for the whole group was at year 1, a mean fall of $0.6 \%(7 \mathrm{mmol} / \mathrm{mol})$ from pre-CSII levels. Mean $\mathrm{HbA} 1 \mathrm{c}$ levels tended to increase thereafter, with the difference (albeit with lower subject numbers) at year 5 and afterwards being lower, but not statistically significantly different, from that prior to CSII commencement. 
Figure 4. Panel $\mathrm{A}$ : $\mathrm{HbA} 1 \mathrm{c}$ results for the first two years following CSII commencement (four monthly average). Panel $\mathrm{B}$ : $\mathrm{HbA} 1 \mathrm{c}$ results for 8 years following CSII commencement (yearly average). Significance $\left({ }^{*} p<0.05\right)$ showed vs. baseline.
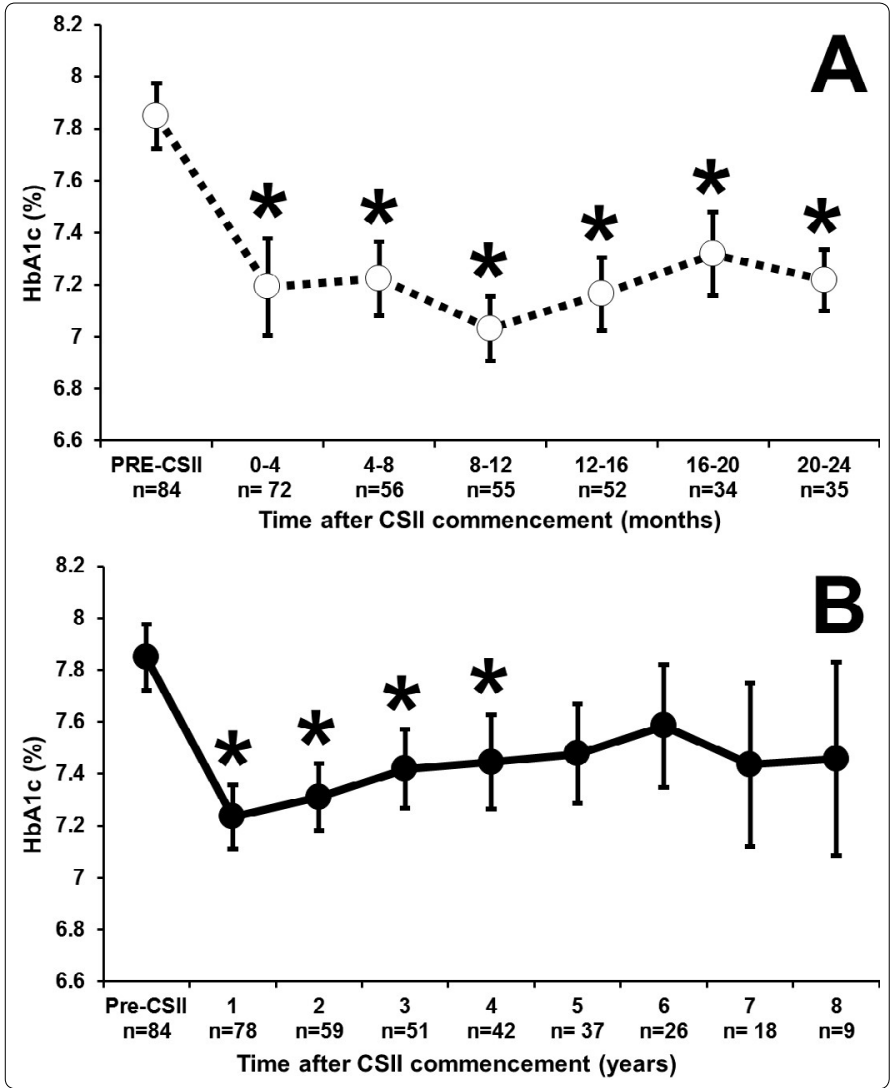

\section{Durability of HbA1c reduction over time by age group}

When mean annual $\mathrm{HbA} 1 \mathrm{c}$ levels post-CSII were compared based on age group (shown in Figure 5). There were no significant differences between age groups.

Figure $5 . \mathrm{HbA} 1 \mathrm{c}$ results into tertiles of baseline age (as CSII commencement) over up to 8 years after CSII commencement. The number of subjects at each time point is shown on the $x$-axis. Significance $\left.{ }^{*} p<0.05\right)$ showed vs. baseline.

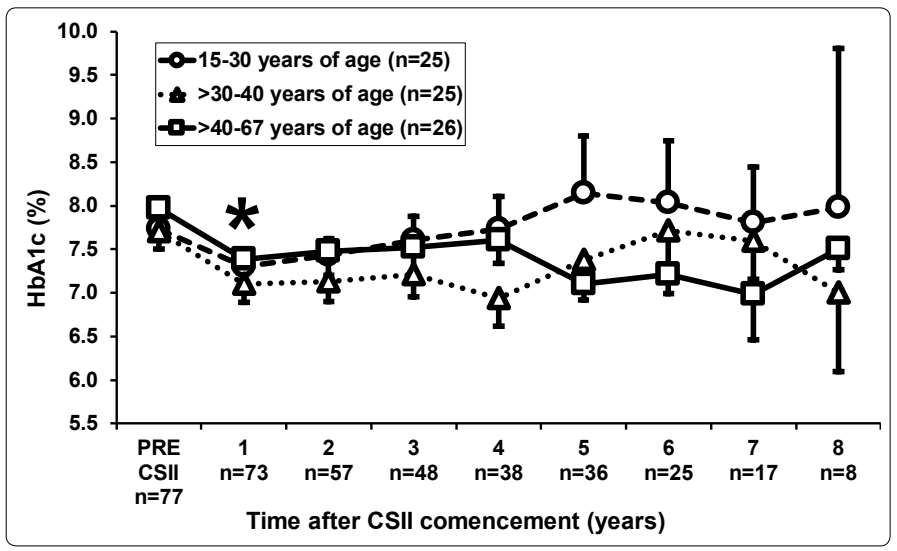

Durability of $\mathrm{HbA1c}$ reduction over time by starting $\mathrm{HbA1c}$ level

The changes in $\mathrm{HbA1c}$ over time when subjects were divided by baseline $\mathrm{HbA} 1 \mathrm{c}$ tertile are shown in Figure 6 . Subjects with the highest starting $\mathrm{HbA1c}$ tended to have higher $\mathrm{HbA1c}$ levels over time, but these differences did not reach statistical significance
Figure 6. $\mathrm{HbA} 1 \mathrm{c}$ results over time divided into tertiles of baseline $\mathrm{HbA} 1 \mathrm{c}$ (at CSII commencement) for up to 8 years after CSII commencement. The number of subjects at each time point is shown on the $x$ axis. Significance $\left({ }^{*} p<0.05\right)$ showed vs. baseline.

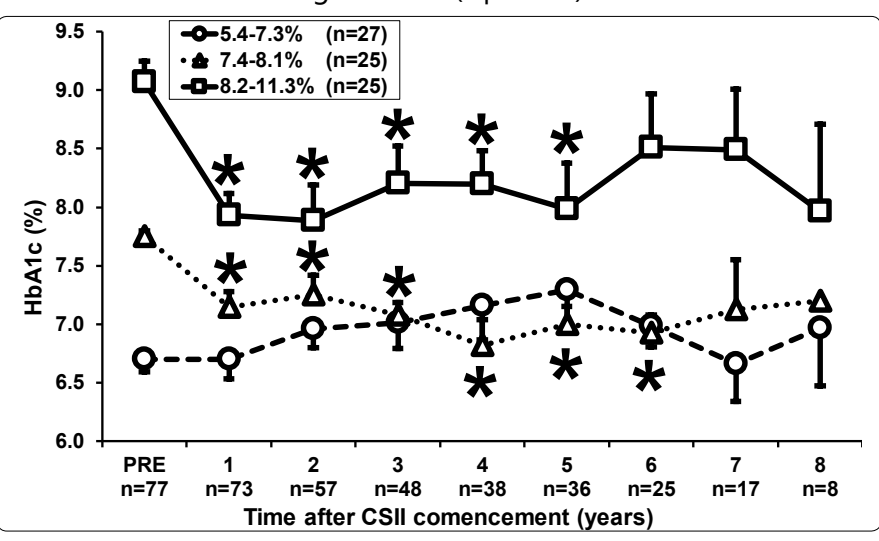

\section{Other clinical variables}

Weight, blood pressure, lipid levels, and urine ACR (described pre-CSII therapy in Table 1) did not change significantly over follow-up. (Data not shown). Only two subjects had increased albuminuria pre-CSII therapy and we are unable to report their change over time as follow-up urine ACR data were not available.

\section{Discussion}

In three linked Victoria, Australia diabetes services, 77 subjects, predominantly females, had adequate clinical and biochemical data from pre- and post-CSII initiation for (a paper-based) Quality Assurance audit. There was a wide range of age, T1D duration and $\mathrm{HbA} 1 \mathrm{c}$ levels at CSII initiation. Whilst there were no major differences in $\mathrm{HbA} 1 \mathrm{c}$ improvement related to gender or age at CSII commencement, diabetes duration and starting $\mathrm{HbA} 1 \mathrm{c}$ were associated with the subsequent change in $\mathrm{HbA} 1 \mathrm{c}$ levels. Mean $\pm \mathrm{SD} \mathrm{HbA} 1 \mathrm{c}$ levels prior to CSII commencement was $7.8 \pm 1.2 \%(62 \pm 13 \mathrm{mmol} /$ mol), with only $19 \%$ of subjects on MDI achieving the recommended $\mathrm{HbA} 1 \mathrm{c}$ target of less than $7 \%(53 \mathrm{mmol} / \mathrm{mol})$ on MDI. During follow-up (range $0.33-8$ ) years on CSII, the $\mathrm{HbA} 1 \mathrm{c}$ nadir was $6.7 \pm 0.8 \%(50 \pm 9 \mathrm{mmol} / \mathrm{mol})$, within the recommended target $\mathrm{HbA} 1 \mathrm{c}<7 \%(53 \mathrm{mmol} / \mathrm{mol})$, achieved a mean of 17 months after CSII commencement. Over $40 \%$ of subjects achieve and maintain a $\mathrm{HbA} 1 \mathrm{c}<7 \%(53 \mathrm{mmol} / \mathrm{mol})$ for up to four years and $69 \%$ achieve a $\mathrm{HbA} 1 \mathrm{c}<7 \%$ (53mmol/ mol) at least once during follow-up. Most subjects first reached a $\mathrm{HbA} 1 \mathrm{c}<7 \%$ within the first 1 or 2 years of CSII commencement. With longer duration of CSII use, HbA1c levels tended to rise from the nadir, but remained significantly below pre-CSII levels for four years. Whilst all tertiles of starting $\mathrm{HbA} 1 \mathrm{c}$ reached a nadir $\mathrm{HbA} 1 \mathrm{c}$ of $7 \%(53 \mathrm{mmol} / \mathrm{mol})$ or below, the subjects with higher $\mathrm{HbA1c}$ levels on MDI achieved larger $\mathrm{HbA} 1 \mathrm{c}$ reductions on CSII therapy than those with better $\mathrm{HbA} 1 \mathrm{c}$ levels at CSII commencement. Participants with shorter T1D duration ( $\leq 12$ years at the time of CSII commencement) also achieved a larger drop in $\mathrm{HbA} 1 \mathrm{c}$ than those with longer diabetes duration. This may relate to lower rates of impaired hypoglycaemia awareness in those with shorter T1D duration, though we did not assess this. 
The majority of patients were using MDI therapy, usually with long acting relatively peak-less insulins (Lantus or Levemir) once or twice a day, with a rapid acting insulin (Novorapid or Humalog or Apidra) pre-meal. Their mean HbA1c $(7.8 \%(62 \mathrm{mmol} / \mathrm{mol}))$ on MDI therapy was slightly better than the national average of $8.1 \%(65 \mathrm{mmol} / \mathrm{mol})$ for Australian adults with Type 1 diabetes[8]. None of our subjects discontinued CSII, in keeping with low national rates of pump cessation (about 1.5\%) [1].

According to Australian reports (AlHW, 2012) based on NDSS data, almost half of CSII users are below 25 years of age [1]. As reflected by Table 1 and Figure 1 we had a wide age range of subjects commencing CSII therapy, with a mean diabetes duration at CSII commencement of 17 years, with a wide range (1 - 43 years), with few (4.7\%) starting CSII within the first two years of their diabetes diagnosis. We recommend that clinicians do not limit their consideration or recommendation of pump therapy to their younger diabetes patients as our data and experience support that older subjects achieve similar glycaemic outcomes.

Whilst lower $\mathrm{HbA} 1 \mathrm{c}$ levels are associated with lower risk of diabetic vascular complications [9], reduced risk of infection [10], improved wound healing [11] and better intellectual function and mental well-being [12], it should not be the sole reason for CSII use or for judging its benefit. In a survey of CSII users in Australia $88 \%$ chose CSII to improve glucose control, and $67 \%$ also desired it for better lifestyle and quality of life [1]. We did not survey quality of life in our subjects, but their ongoing use of CSII suggests their balance of benefits and advantages of CSII use were favourable. In other pump studies, including our own, CSII use was associated with improved quality of life [13-18].

In our clinical audit subjects achieved a mean $\mathrm{HbA} 1 \mathrm{c}$ reduction of $1.1 \%(12 \mathrm{mmol} / \mathrm{mol})$, with more than a doubling of subjects achieving a $\mathrm{HbA} 1 \mathrm{c}<7 \% \quad(53 \mathrm{mmol} / \mathrm{mol})$, the generally recommended target in clinical practice, however we acknowledge that $\mathrm{HbA} 1 \mathrm{c}$ targets should be individualised [19]. For example, for elderly people, patients with reduced hypoglycaemia awareness, or those living alone, a higher $\mathrm{HbA} 1 \mathrm{c}$ target may be prudent. On average the $\mathrm{HbA} 1 \mathrm{c}$ levels and reductions observed are greater than those reported in recent studies [3,20]. In Sweden 10 clinics conducted a similar audit on patients with Type 1 diabetes with a mean $\mathrm{HbA} 1 \mathrm{c}$ of $8.4 \%(68 \mathrm{mmol} / \mathrm{mol})$ and reported a mean $\mathrm{HbA} 1 \mathrm{c}$ reduction of $0.5 \%(5 \mathrm{mmol} / \mathrm{mol})$ after 1-year of CSII use [20]. These differences likely reflect patient selection and differences in clinical practice. That all subjects in our study reached similar $\mathrm{HbA1c}$ nadirs irrespective of their starting $\mathrm{HbA1c}$ level may reflect patient preference so as to limit their hypoglycaemia risk and frequency, which we did not record due to challenges in the accuracy of data collection, effects of impaired hypoglycaemic awareness, which is not uncommon in T1D, and the absence of continuous glucose monitoring use.

Analysis of our patients' $\mathrm{HbA} 1 \mathrm{c}$ results by tertiles of age at CSII commencement revealed similar $\mathrm{HbA} 1 \mathrm{c}$ benefit between age groups, with similar time taken to reach their $\mathrm{HbA} 1 \mathrm{c}$ nadir. Similarly, Matejko et al. reported that CSII users aged $\geq 50$ years, achieved similar $\mathrm{HbA1c}$ benefit as those $<50$ years [21].Our outcomes support that adults with T1D of all ages should be considered for CSII therapy. We did find that shorter T1D duration subjects achieved greater $\mathrm{HbA} 1 \mathrm{c}$ reductions with CSII use, which may relate to less impaired hypoglycaemia awareness, which is more likely with longer diabetes duration, but we did not record hypoglycaemia awareness. Our results and that of other investigators, such as Matejko, dispel the not uncommon notion that youth perform better than more mature adults with regard to glycaemic benefit with pump use in spite of differences in the hormonal milieu and lifestyle. However, we recognise that self-selection bias is present. Our audit is not able to discern the effects of education and time spent with the diabetes care team that would have been given to those subjects starting CSII therapy, nor assess whether the clinician time spent differed between age groups or by starting $\mathrm{HbA} 1 \mathrm{c}$ level.

The weight, blood pressure and lipid levels of our patients did not change significantly over time. The average lack of weight change with CSII use is in keeping with prior reports. [22]. Whilst the reduction in insulin dose on CSII vs. MDI therapy may be associated with reduced appetite, others may gain weight due to the greater flexibility of food intake and lower $\mathrm{HbA} 1 \mathrm{c}$ reducing (calorie losing) glycosuria. Whilst better glycaemic control is usually associated with improved lipid levels, there were no significant changes. We did not fully record use of and/ or changes in diet and lipid or blood pressure medications. DahlJørgensen et al reported reductions in albuminuria with CSII use [23], likely related to better glycaemia. There was no change in ACR in our subjects, though all but two had normal levels, and we acknowledge that the urine $A C R$ is a screening test. Epidemiologic studies, such as the Swedish Diabetes Registry v] have demonstrated lower vascular complication and mortality rates with CSII use than with $\mathrm{MDI}$ use, which may relate to better $\mathrm{HbA} 1 \mathrm{c}$ levels, and potentially (not reported) also to lower glycaemic variability and lower exogenous insulin doses.

Study limitations include incomplete follow-up of all subjects commencing CSII. Since undertaking this audit an electronic data-base has been adopted, so completeness and follow-up of future audits will likely be better and less labour intensive. It is likely that the CSII users received more time and education for the clinicians than those subjects continuing on MDI. We did not record clinician time to achieve the CSIIrelated improved glucose control, but in a subsequent prospective study we demonstrated that it is significantly longer for nurses, but similar for doctors and dietitians to support CSII than MDI users [2]. As is common in our clinic and in that of many of our colleagues, the majority of our pump users were female; hence the relatively small number of males evaluated does not enable robust comparison of potential gender differences in responses. Similarly, very few subjects had chronic diabetes complications; hence we are unable to discern if their metabolic responses differed and if this had any effect on their chronic complications. As this is an audit of clinical practice rather than a randomised controlled trial, there may be a (self-) selection bias of pump users being more motivated or more affluent than the general population of adults with Type 1 diabetes. A strength is that this audit 
represents 'real-world' clinical practice at different clinical sites and with several years of follow-up.

In conclusion, we have demonstrated in our clinical practices that adult men and women with Type 1 diabetes across a wide range of age, diabetes duration and initial $\mathrm{HbA} 1 \mathrm{c}$ levels do well with CSII use, with sustained HbA1c reductions and no changes in weight, blood pressure, lipids or urine $\mathrm{ACR}$ over time. $\mathrm{HbA} 1 \mathrm{c}$ reductions were greater in those starting CSII therapy with the highest $\mathrm{HbA} 1 \mathrm{c}$ level and with shorter diabetes duration, and were similar and wellmaintained in all age groups.

Acknowledgements: Authors thank all medical clinic, hospital and pathology laboratory staff for assistance with data retrieval and their input into patient care.

Authors Disclosure Statement: KKC was supported by a travel grant from Global Links, USA. AJJ and DNO have received honoraria from and conducted (investigator and industry initiated) trials from Medtronic and Sanofi-Aventis, Animas, Novo and Eli Lily. AJ is on Advisory Boards for Medtronic and Abbott and DNO is on an Advisory Board for Abbott.RJM has received honoraria for lectures from Eli Lilly, Novo Nordisk, Sanofi-Aventis, Astra Zeneca, Merck Sharp \& Dohme, Bayer and Norvartis and travel support from Novo Nordisk, SanofiAventis, Boehringer Ingelheim and Astra Zeneca. He has received research grants from Novo Nordisk and Servier, conducted industry initiated trials for Novo Nordisk, Bayer, Johnson \& Johnson, Astra Zeneca, Abbive and Versartis and on the Advisory Board for the Boehringer Ingelheim - Eli Lilly Alliance and Sanofi-Aventis.

\section{Conflicts of Interest: The authors report no conflicts of interest.}

\section{References}

1. Australian Institute of Health and Welfare (AlHW). Insulin pump use in Australia. Diabetes Series, 2012, Number 18. Canberra. Cat. no. CVD 58. Accessed: 15 Nov 2014.

2. Xu S, Alexander K, Bryant $\mathrm{W}$, Cohen $\mathrm{N}$, Craig ME, Forbes $\mathrm{M}$, et al. Healthcare Professional Requirements for the Care of Adult Diabetes Patients Managed with Insulin Pumps in Australia. Intern Med J. 2015; 45(1):86-93. doi: 10.1111/imj.12619.

3. Misso ML, Egberts KJ, Page M, O'Connor D, Shaw J. (2010) Continuous subcutaneous insulin infusion (CSII) versus multiple insulin injections for type 1 diabetes mellitus. Cochrane Database Syst Rev. 2010; 20(1):CD005103. doi: 10.1002/14651858.CD005103.pub2.

4. Wilkinson J, Kilmartin G, Kilmartin J, et al. Positive initial insulin pump therapy experience in a rural setting. InfuSystems Asia, 2010; 5(4).

5. Cohen ND, Hong ES, Van Drie C, Balkau B, Shaw J. Long-term metabolic effects of continuous subcutaneous insulin infusion therapy in type 1 diabetes. Diabetes Technol Ther. 2013;15(7):544-9. doi: 10.1089/ dia.2012.0331

6. Foskett DC, Price DA, Lang EG. An evaluation of insulin pump therapy in young people in three regional centres in Queensland. Paper presented at the Australian Diabetes Society and Australian Diabetes Educators Association Annual Scientific Meeting. Perth Convention and Exhibition Centre, WA. 2011.

7. Januszewski AS, Karschimkus CS, McAuley S, O'Neal DN, Jenkins AJ. Better Vascular Health Profile in Type 1 Diabetes CSII users. Proceedings of 72nd Scientific Session of American Diabetes Association, Philadelphia PA, 8 - 12 June, 2012, Diabetes 2012 (poster presentation)
8. Australian National Diabetes Information Audit \& Benchmarking (ANDIAB). ANDIAB 2011 Final Report. December 2011.

9. The Diabetes Control and Complications Trial Research Group. The effect of intensive treatment of diabetes on the development and progression of long-term complications in insulin-dependent diabetes mellitus. N Eng J Med .1993;329:977-86. doi: 10.1056/NEJM199309303291401

10. Alserius $\mathrm{T}$, Anderson RE, Hammar $\mathrm{N}$, Nordqvist $\mathrm{T}$, Ivert $\mathrm{T}$. Elevated glycosylated haemoglobin $(\mathrm{HbA} 1 \mathrm{c})$ is a risk marker in coronary artery bypass surgery. Scand Cardiovasc J. 2008;42(6):392-8. http://dx.doi. org/10.1080/14017430801942393 http://www.tandfonline.com/doi/ abs/10.1080/14017430801942393?journalCode=icdv20

11. Marston WA; Dermagraft Diabetic Foot Ulcer Study Group. Risk factors associated with healing chronic diabetic foot ulcers: the importance of hyperglycemia. Ostomy Wound Manage. 2006;52(3):26-8.

12. Martin DD, Davis EA, Jones TW. Acute effects of hyperglycaemia in children with type 1 diabetes mellitus: the patient's perspective. J Pediatr Endocrinol Metab. 2006;19(7):927-36.

13. Cohen N, Minshall ME, Sharon-Nash L, Zakrzewska K, Valentine WJ, Palmer AJ. Continuous subcutaneous insulin infusion versus multiple daily injections of insulin: economic comparison in adult and adolescent type 1 diabetes mellitus in Australia. Pharmacoeconomics. 2007;25(10): 881-97.

14. Giménez $M$, Lara $M$, Conget I. Sustained efficacy of continuous subcutaneous insulin infusion in type 1 diabetes subjects with recurrent non-severe and severe hypoglycemia and hypoglycemia unawareness: a pilot study. Diabetes Technol Ther. 2010;12(7):517-21. doi: 10.1089/dia.2010.0028.

15. Golden SH, Sapir T. Methods for insulin delivery and glucose monitoring in diabetes: summary of a comparative effectiveness review. J Manag Care Pharm. 2012;18(6):1-17.

16. Nørgaard K, Sohlberg A, Goodall G. Cost-effectiveness of continuous subcutaneous insulin infusion therapy for type 1 diabetes. Ugeskr Laeger. 2010;172(27):2020-5.

17. Jenkins AJ, Krishnamurthy B, Best JD, et al. Evaluation of an algorithm to guide patients with type 1 diabetes treated with continuous subcutaneous insulin infusion on how to respond to real-time continuous glucose levels: a randomized controlled trial. Diabetes Care. 2010;33(6):1242-8. http://dx.doi.org/10.2337/dc09-1481 http://care. diabetesjournals.org/content/33/6/1242.abstract

18. Jenkins AJ, Krishnamurthy $B$, Best JD, et al. An algorithm guiding patient responses to real-time-continuous glucose monitoring improves quality of life. Diabetes Technol Ther. 2011;13(2):105-109. 10.1089/ dia.2010.0139. https://www.ncbi.nlm.nih.gov/pubmed/21284476

19. Cheung NW, Conn JJ, d'Emden MC, et al. Position statement of the Australian Diabetes Society: individualisation of glycated haemoglobin targets for adults with diabetes mellitus. Med J Aust. 2009;191(6):339-344.

20. Carlsson BM, Attvall $S$, Clements $M$, et al. Insulin pump-long-term effects on glycemic control: an observational study at 10 diabetes clinics in Sweden. Diabetes Technol Ther. 2013;15(4):302-307. doi: 10.1089/ dia.2012.0286

21. Matejko B, Cyganek K, Katra B, et al. Insulin pump therapy is equally effective and safe in elderly and young type 1 diabetes patients. Rev Diabet Stud. 2011;8(2):254-8. doi: 10.1900/RDS.2011.8.254

22. Hanaire-Broutin $\mathrm{H}$, Melki V, Bessières-Lacombe $\mathrm{S}$, Tauber JP. Comparison of continuous subcutaneous insulin infusion and multiple daily injection regimens using insulin lispro in type 1 diabetic patients on intensified treatment: a randomized study. The Study Group for the Development of Pump Therapy in Diabetes. Diabetes Care. 2000;23(9):1232-5.

23. Dahl-Jørgensen K, Hanssen KF, Kierulf P, Bjøro T, Sandvik L, Aagenaes O. Reduction of urinary albumin excretion after 4 years of continuous subcutaneous insulin infusion in insulin-dependent diabetes mellitus. The Oslo Study. Acta Endocrinol (Copenh). 1988;117(1):19-25.

24. Steineck I, Cederholm J, Eliasson B, et al. Insulin pump therapy, multiple daily injections, and cardiovascular mortality in 18,168 people with type 1 diabetes: observational study. BMJ. 2015; 350:h3234. doi: http://dx.doi. org/10.1136/bmj.h3234 